\title{
The Interactive Effects of Daytime High Temperature and Humidity on Growth and Endogenous Hormone Concentration of Tomato Seedlings
}

\author{
Yanjiao Zheng \\ Collaborative Innovation Center on Forecast and Evaluation of \\ Meteorological Disasters, Nanjing University of Information Science and \\ Technology, Nanjing 210044, China
}

Zaiqiang Yang

Collaborative Innovation Center on Forecast and Evaluation of Meteorological Disasters, Nanjing University of Information Science and Technology, Nanjing 210044, China, and Jiangsu Provincial Key Laboratory of Agrometeorology, Nanjing 210044, China

\section{Chao Xu, Lin Wang, Haijing Huang, and Shiqiong Yang Collaborative Innovation Center on Forecast and Evaluation of Meteorological Disasters, Nanjing University of Information Science and Technology, Nanjing 210044, China}

Additional index words. dry matter accumulation, soluble sugar, free amino acids, high temperature stress

\begin{abstract}
High temperature and high relative humidity (RH) are one of the most serious agricultural meteorological disasters that limit the production capacity of agricultural facilities. However, little information is available on the precise interaction between these factors on tomato growth. The objectives of this study were to determine the effect of high temperature under different $\mathrm{RH}$ levels on tomato growth and endogenous hormones and to determine the optimal $\mathrm{RH}$ for tomato seedling growth under high temperature environment. Two high temperature $\left(38 / 18{ }^{\circ} \mathrm{C}, 41 / 18{ }^{\circ} \mathrm{C}\right)$ and three relative humidity $(50 \pm$ $5 \%, 70 \pm 5 \%, 90 \pm 5 \%$ ) orthogonal experiments were conducted, with $28 / 18{ }^{\circ} \mathrm{C}, 50 \pm 5 \%$ (CK) as control. The results showed that the dry matter accumulation of tomato plants under high temperature environment was significantly lower than that of $\mathrm{CK}$. At $38{ }^{\circ} \mathrm{C}$, the dry matter accumulation with $70 \%$ relative humidity was not significantly different from that of $\mathrm{CK}$; at $41{ }^{\circ} \mathrm{C}$, dry matter accumulation with $70 \%$ and $90 \%$ relative air humidity was significantly greater than that of $50 \%$. The concentrations of soluble sugar and free amino acids in all organs in high temperature-treated plants were significantly higher than that in CK. As relative humidity increased, soluble sugar concentrations of each organ decreased, and the free amino acid concentrations increased. Cytokinin (ZT) and indole acetic acid (IAA) concentrations in tomato buds were significantly lower than in CK under high temperature conditions. The lower the RH, the lower the content of ZT and IAA. The gibberellin $\left(G_{3}\right)$ and abscisic acid (ABA) concentrations were higher than in $\mathrm{CK}$ under high temperatures. $\mathrm{GA}_{3}$ concentrations decreased and $\mathrm{ABA}$ concentrations were augmented with increased humidity. The differences of tomato seedling growth indices and apical bud endogenous hormone concentrations between RHs under high temperature conditions were significant. Raising $\mathrm{RH}$ to $\mathbf{7 0 \%}$ or higher under high temperature conditions could be beneficial to the growth of tomato plants. The results contribute to a better understanding of the interactions between microclimate parameters inside a Venlo-type glass greenhouse environment, in a specific climate condition, and their effects on the growth of tomato.
\end{abstract}

Tomato (Lycopersicon esculentum Mill.) is native to the western plateau of South America, it adapts to the dry and cool climate of the highland near the equator of the origin, so it is not resistant to high temperature and humidity (Harel et al., 2014). The optimal growth temperature for tomato growth is 18.3 to $32.2{ }^{\circ} \mathrm{C}$, and the relative humidity is $50 \%$ to $70 \%$ (Shamshiri et al., 2018b), above $35{ }^{\circ} \mathrm{C}$, the growth is slow, and at $40{ }^{\circ} \mathrm{C}$ the plants stop growing (Yang et al., 2018a).
Temperature is one of the most important environmental factors affecting tomato growth (Shamshiri et al., 2018b). The Intergovernmental Panel on Climate Change (IPCC) report indicated that global average temperatures had increased by about $1{ }^{\circ} \mathrm{C}$ since the preindustrial era and projected that global average warming was likely to reach $1.5^{\circ} \mathrm{C}$ between 2030 and 2052 at the current rate of anthropogenic greenhouse gas (GHG) emissions (Intergovernmental Panel on Climate
Change, 2018). Thus, global warming will threaten the production of horticultural tomatoes more frequently and severely. In the late spring and early summer in China, the temperature difference between day and night is large. During the day, the temperature in the greenhouse is higher due to the strong light, but it is low at night, so the phenomenon of high day temperature and normal night temperature occurs (Shamshiri et al., 2017b, 2018a, 2020). Research has shown that the temperature and RH outside the greenhouse were between 28 and $33{ }^{\circ} \mathrm{C}$ and $70 \%$ to $85 \%$, but the internal microclimate reached 68 and $70{ }^{\circ} \mathrm{C}$ and $\mathrm{RH}=20 \%$ to $35 \%$, resulting in air vapor pressure deficit (VPD) between 18 and $21 \mathrm{kPa}$ (Shamshiri et al., 2017a). The excess heat imposed by direct solar radiation causes substantial increase in inside air temperature, 20 to $30{ }^{\circ} \mathrm{C}$ higher than the outside (Shamshiri et al., 2017a). At this time, high temperature has become an important limiting factor for horticultural tomatoes.

High temperature stress causes poor pollination of tomato plants and reduces seed setting rate (Cruz-Ortega et al., 2002; Singh et al., 2015), plant dwarfing, aging (Rohn et al., 2002; Wang et al., 2018; Zhang et al., 2005) and fruit quality decline (Mulholland et al., 2003) and also corresponds to a low optimality degree and comfort ratio of the microclimate (Shamshiri et al., 2020). Although high temperature stress has many adverse effects on plants, we can reduce plant transpiration by increasing RH accordingly alleviate damage caused by high temperature stress (Peet et al., 2003; Shamshiri et al., 2018b; Wang et al., 2017, 2018; Xue et al., 2010; Yang et al., 2018a, 2018b; Zhao et al., 2019). However, temperature and humidity exist at the same time, affecting and interacting with each other. Excessive temperature and humidity are likely to cause early plant senescence, shorten the growth period, increase vulnerability to pests and diseases, and affect fruit yield and quality (Li, 2014).

Carbon and nitrogen metabolism are the most basic metabolic pathways of plants, and their intensity and coordination degree have a significant impact on plant growth and development (David, 2002). Soluble sugar is the first product of plant photosynthesis; it can also be used as an osmotic adjustment substance when the plant is under stress, adjust the concentration of cell fluid, and enhance the resistance (Barickman et al., 2016; Zhang et al., 2005). Free amino acid is an intermediate product of nitrogen metabolism. Its content increases rapidly under adverse conditions, and it accumulates in large amounts without destroying the biochemical reaction in the cell (Parida and Das, 2005). The increase is positively correlated with heat resistance (Jin, 2011). Endogenous hormones (ABA, IAA, $\mathrm{GA}_{3}$, and $\mathrm{ZT}$ ) are more sensitive to temperature changes and respond quickly to high temperature stress, and thus they are seen as an important signal substance for plants to adapt to adversity (Zou et al., 2019). Zhang et al. (2013) showed 
that under high temperature treatment, the content of $\mathrm{GA}_{3}$ and IAA in rice anthers decreased, leading to the reduction of pollenpromoting substances in pollen and the potential for pollen germination, while the increase of ABA level in anthers increases the adaptability of anthers to high temperature conditions.

Future climate scenarios predict that surface temperature and precipitation will rise in East Asia (Chevuturi et al., 2018). Although many previous studies have reported the effect of high temperature and $\mathrm{RH}$ on tomato yield and quality, little information is available on the precise interaction between them on tomato growth. Therefore, this study aimed to 1) evaluate the effects of high temperature and three levels of $\mathrm{RH}$ on tomato external morphology, dry matter accumulation, and soluble sugar and free amino acid content and 2) explore the interaction of high temperature and humidity on the content of tomato endogenous hormones (ABA, IAA, $\mathrm{GA}_{3}, \mathrm{ZT}$ ) and screen out the optimal humidity for tomato growth under high temperature environment. The results contribute to a better understanding of the interactions between microclimate parameters inside a Venlo-type glass greenhouse environment in a specific climate condition, and their effects on the growth of tomato.

\section{Material and Methods}

Experimental design. The experiment was carried out from Apr. to Sept. 2017 in a Venlo-type glass greenhouse and in an intelligent artificial climate chamber at Nanjing University of Information Science and Technology. The experiment materials were 'Jinfen5' tomato seedlings (Lycopersicon esculentum Mill. 'Jinfen 5'). Seedlings were grown in a greenhouse in early April at a temperature of 22 to $28{ }^{\circ} \mathrm{C}$ and $\mathrm{RH}$ of $45 \%$ to $55 \%$. When the tomato seedlings reached the three-leaf center, a tomato plant with good growth and uniformity was chosen and transplanted into a $28 \mathrm{~cm}($ high) $\times 34 \mathrm{~cm}$ (internal diameter) pot. The contents of soil organic carbon, nitrogen, available phosphorus, and available potassium in the pot were 11,600 , 1190, 29.3, and $94.2 \mathrm{mg} \cdot \mathrm{kg}^{-1}$, respectively. Soil $\mathrm{pH}$ was 6.8 and soil texture was medium loam. When the seedlings reached $15 \mathrm{~cm}$ in height, the potted plants were placed in an artificial climate box (TPG1260; Thermoline, NSW, Australia). Two high-temperature

Received for publication 18 May 2020. Accepted for publication 1 July 2020.

Published online 4 September 2020.

We are grateful for research grants from the National Natural Science Foundation of China (41775104), National Key Research and Development Plan of China (2019FYD1002202).

Z.Y. is the corresponding author. E-mail: yzq@ nuist.edu.cn.

This is an open access article distributed under the CC BY-NC-ND license (https://creativecommons. org/licenses/by-nc-nd/4.0/). treatment conditions were set in the test: 38 / $18{ }^{\circ} \mathrm{C}\left(\mathrm{H}_{1}\right), 41 / 18{ }^{\circ} \mathrm{C}\left(\mathrm{H}_{2}\right)$ (day/night temperature); three air $\mathrm{RH}$ treatments were set under each high temperature condition (the error is controlled at 5\%): $50 \%\left(\mathrm{RH}_{50 \%}\right)$, $70 \%\left(\mathrm{RH}_{70 \%}\right)$, and $90 \%\left(\mathrm{RH}_{90 \%}\right)$. Conditions of $28 / 18{ }^{\circ} \mathrm{C}$ and $50 \%$ relative humidity were used as controls (CK). Six treatments were set up in an orthogonal experiment design, with $28 / 18{ }^{\circ} \mathrm{C}$, and $50 \pm 5 \%(\mathrm{CK})$ as control (Table 1). During the experiment, the temperature change in the artificial climate box is shown in Fig. 1, and the RH during the day was set to $50 \% / 70 \% / 90 \%$ and at night to $80 \%$. The photoperiod of the artificial climate box was set to $12 \mathrm{~h} / 12 \mathrm{~h}$ (day/night), and photosynthetically active radiation was set to $800 \mu \mathrm{mol} \cdot \mathrm{s}^{-1} \cdot \mathrm{m}^{-2}$ from 0600 to $11: 00 \mathrm{HR}$, $1000 \mu \mathrm{mol} \cdot \mathrm{s}^{-1} \cdot \mathrm{m}^{-2}$ from 1100 to $1400 \mathrm{HR}$, $800 \mu \mathrm{mol} \cdot \mathrm{s}^{-1} \cdot \mathrm{m}^{-2}$ from 1400 to $1800 \mathrm{HR}$, and 0 $\mu \mathrm{mol} \cdot \mathrm{s}^{-1} \cdot \mathrm{m}^{-2}$ from 1800 to $0600 \mathrm{HR}$. Water and nutrient conditions in the potted soil were consistent during the experiment.

The temperature, $\mathrm{RH}$, and the solar radiation inside the greenhouse were measured by thermistor thermometer and relative humidity probes (CR3000; Campbell Scientific, Logan, UT) with respective accuracies of $\pm 0.3{ }^{\circ} \mathrm{C}$ and $\pm 5 \% \mathrm{RH}$. The data were automatically recorded at 10-min intervals. During the test, air temperature ranged from 13.3 to $33.3{ }^{\circ} \mathrm{C}$, RH was between $45 \%$ and $75 \%$, and daily solar radiation was $7.3-205.4 \mathrm{~W} \cdot \mathrm{m}^{-2}$.

Measurements and samples were taken before treatment (day 0 ) and at 3, 6, 9, and $12 \mathrm{~d}$ of each treatment. We picked a whole tomato seedling and measured the dry matter weight of each organ separately. Then we selected another tomato seedling in the same treatment, took the main stem top bud to measure the endogenous hormone content, and used the remaining roots, stems, and leaves to measure the soluble sugar and free amino acid content. Because the cells in the top bud grow rapidly and are metabolized vigorously, and it is the most sensitive and easiest to measure under high temperature, we chose the top bud of tomato seedlings to measure the endogenous hormone.

Determination of plant morphological indicators. The heights of the tomato seedlings (from the base to the growth point) were measured using a ruler (centimeters). The diameters of the base of the stems were measured using a vernier caliper (millimeters), and the leaf areas were measured using a LI-3100C (LI-COR Biosciences, Lincoln, NE) leaf area meter (square centimeters).

Dry matter weight. We selected the whole tomato seedlings under CK and high temperature treatment, dug them out of the pots, and cleaned them. The different organs (roots, stems, leaves) were put in an oven at $105^{\circ} \mathrm{C}$ for $5 \mathrm{~min}$ and then dried to a consistent weight in an $85{ }^{\circ} \mathrm{C}$ oven. A one-thousandth electronic balance (ES-220D; Shanghai Xinheng Electronics, Shanghai, China) was used to determine the dry weight of each organ, and three replicates for each treatment were taken.
Table 1. Experimental design table.

\begin{tabular}{lcc}
\hline Treatments & Temperature $\left({ }^{\circ} \mathrm{C}\right)$ & Humidity (\%) \\
\hline $\mathrm{CK}$ & $28 / 18$ & $50 \pm 5$ \\
$\mathrm{H}_{1} \mathrm{RH}_{50 \%}$ & $38 / 18$ & $50 \pm 5$ \\
$\mathrm{H}_{1} \mathrm{RH}_{70 \%}$ & $38 / 18$ & $70 \pm 5$ \\
$\mathrm{H}_{1} \mathrm{RH}_{90 \%}$ & $38 / 18$ & $90 \pm 5$ \\
$\mathrm{H}_{2} \mathrm{RH}_{50 \%}$ & $41 / 18$ & $50 \pm 5$ \\
$\mathrm{H}_{2} \mathrm{RH}_{70 \%}$ & $41 / 18$ & $70 \pm 5$ \\
$\mathrm{H}_{2} \mathrm{RH}_{90 \%}$ & $41 / 18$ & $90 \pm 5$ \\
\hline
\end{tabular}

Determination of soluble sugars and free amino acids. Soluble sugar concentrations of different organs (root, stem, leaf) were determined using the anthrone-sulfuric acid colorimetric method and free amino acid concentrations were determined using ninhydrin calorimetry (Zheng et al., 2016).

Determination of concentration of endogenous hormones. The concentration of endogenous hormones (IAA, $\mathrm{GA}_{3}, \mathrm{ABA}$, and $\mathrm{ZT}$ ) was determined based on the method of with minor improvement (Hou et al., 2008). A $1.00 \mathrm{-g}$ top bud sample was ground to a fine powder in the presence of liquid nitrogen and then extracted with $20 \mathrm{~mL}$ of an $80 \% \mathrm{v} / \mathrm{v}$ methanol solution containing $20 \mu \mathrm{g} / \mathrm{L}$ of antioxidant BHT at $4{ }^{\circ} \mathrm{C}$ for $12 \mathrm{~h}$. The extract was centrifuged at $13,000 \mathrm{r} / \mathrm{min}$ for $15 \mathrm{~min}$ to obtain a supernatant. The residue was added to $8 \mathrm{~mL}$ of $80 \%$ methanol reextracted twice in the same manner. The whole filtrate was concentrated under reduced pressure at $35{ }^{\circ} \mathrm{C}$ to the original volume of $1 / 3$, and then adjusted to a $\mathrm{pH}$ of 8.0 with $1 \mathrm{~mol} / \mathrm{L}$ $\mathrm{Na}_{2} \mathrm{HPO}_{4}$. Decolorization was carried out three to five times by adding the same volume of petroleum ether. After discarding the ester phase, $0.1 \mathrm{~g}$ of polyvinylpolypyrrolidone (PVPP) was added to absorb the phenolic substance, and the shaker was shaken at room temperature for $30 \mathrm{~min}$. The PVPP was discarded by filtration, and the filtrate was adjusted to a $\mathrm{pH}$ of 3 with $2 \mathrm{~mol} / \mathrm{L}$ citric acid. Equivalent volume of ethyl acetate was extracted three to five times, and the ester phase was combined and concentrated to dryness under reduced pressure at $35{ }^{\circ} \mathrm{C}$. The residue was dissolved in $3 \mathrm{~mL}$ of $\mathrm{pH} 3.5$ phosphate buffer and passed through a preconditioned C18 SPE column (Sep-Pak; Waters, Milford, MA, $500 \mathrm{mg}, 6 \mathrm{~mL}$ ) to further purify $\mathrm{GA}_{3}$, IAA, ABA, and $\mathrm{ZT}$. The reconstituted eluate was filtered using a $0.45 \mu \mathrm{m}$ microfiber filter before high performance liquid chromatography analysis (Shao et al., 2016). A column thermostat was set at $30{ }^{\circ} \mathrm{C}$, and the flow rate was $1.0 \mathrm{~L} \cdot \mathrm{min}^{-1}$ throughout the separation.

Data Processing and Analysis. The data reported in all tables and figures are expressed as the average of three repeated observations. Analysis of variance was employed with the high temperature, $\mathrm{RH}$, and treatment days as the three fixed factors and was used to assess variations in the external morphological indicators, dry matter accumulation, soluble sugar content, free amino acid content, and endogenous hormone content. Differences between all treatments were detected using Duncan's multiple 
range test at the 0.05 significance level using the SPSS 19.0 software (SPSS Inc., Chicago, IL). All of the figures were generated using Origin Pro 8.0 software (OriginLab, Northampton, MA).

\section{Results}

External form indicator. There were striking differences in the responses of seedling height to $\mathrm{RH}$ at different temperatures (Table 2). The plant height under $\mathrm{RH}_{70 \%}$ and $\mathrm{RH}_{90 \%}$ was significantly greater than that of $\mathrm{CK}$, but the difference in stem diameter under all treatments was generally small; the $\mathrm{RH}_{70 \%}$ and $\mathrm{RH}_{90 \%}$ treatment in particular was not significantly different from $\mathrm{CK}$, and the leaf area treated with $\mathrm{H}_{2} \mathrm{RH}_{90 \%}$ was significantly larger than that of CK. However, in the high temperature environment, plant height, stem diameter, and leaf area of tomato seedlings under $\mathrm{RH}_{50 \%}$ were less than $\mathrm{CK}$, which becomes more significant as the treatment time was extended. Under the same high temperature treatment, the plant height and stem diameter were the highest in $\mathrm{RH}_{90 \%}$, and the $\mathrm{RH}_{70 \%}$ and $\mathrm{RH}_{50 \%}$ treatments decreased sequentially. At the end of the treatment (12 d), the increase in stem diameter and leaf area under $\mathrm{H}_{1} \mathrm{RH}_{70 \%}$ was greater than that before the treatment $(0 \mathrm{~d})$, with an increase of $0.8 \mathrm{~mm}$ and $207.73 \mathrm{~cm}^{2}$, respectively.

Dry matter accumulation. The interaction of daytime high temperature and $\mathrm{RH}$ has different effects on the dry matter accumulation of tomato plants (Fig. 2). Under normal temperature and humidity conditions (CK), tomato seedlings had the largest dry matter, which increased with time. Under $38^{\circ} \mathrm{C}$, the dry matter accumulation at $3 \mathrm{~d}$ was not significantly different from that of $\mathrm{CK}$. After $6 \mathrm{~d}$ of treatment, the $\mathrm{RH}_{50 \%}$ and $\mathrm{RH}_{90 \%}$ were significantly less than $\mathrm{CK}$. At the end of the treatment, the dry matter accumulation under $\mathrm{RH}_{70 \%}, \mathrm{RH}_{90 \%}$, and $\mathrm{RH}_{50 \%}$ were $14.755 \%$, $31.554 \%$, and $35.723 \%$ lower than CK, respectively. The difference between $\mathrm{RH}_{70} \%$ and $\mathrm{CK}$ was not significant, which was significantly greater than $\mathrm{RH}_{50 \%}$ and $\mathrm{RH}_{90 \%}$. At

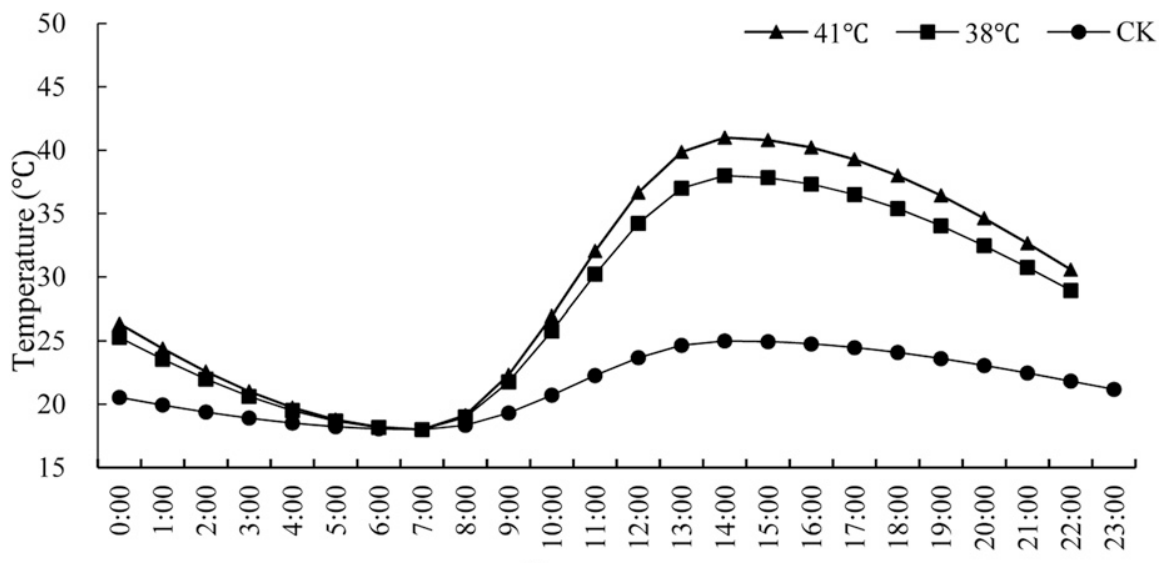

Time

Fig. 1. Temperature changes in the artificial climate box. $41^{\circ} \mathrm{C}$, the dry matter accumulation after $6 \mathrm{~d}$ of treatment was significantly less than $\mathrm{CK}$, and as the processing time increased, the gap became more obvious. After $12 \mathrm{~d}$ of treatment, the dry matter accumulation under $\mathrm{RH}_{90 \%}, \mathrm{RH}_{70 \%}$, and $\mathrm{RH}_{50 \%}$ was $27.294 \%$, $35.232 \%$, and $42.562 \%$ lower than that of $\mathrm{CK}$, respectively. In the three humidity treatments, $\mathrm{RH}_{70 \%}$ and $\mathrm{RH}_{90 \%}$ were significantly greater than $\mathrm{RH}_{50 \%}$. In general, the dry matter accumulation under $\mathrm{H}_{1}$ was slightly greater than that of $\mathrm{H}_{2}$.

Soluble sugar concentrations. Under normal temperature and humidity conditions (CK), the content of soluble sugar in the leaves, stems and roots of tomatoes had a small range of variation, floating between 20.3 and 25.0 $\mathrm{mg} \cdot \mathrm{g}^{-1}$, while in the high temperature environment, the content increased rapidly. With extension of the treatment time, the content showed a significant increase trend, significantly higher than the control CK (Fig. 3). Under the same high temperature treatment, $\mathrm{RH}_{50 \%}$ treatment (normal humidity) had the highest soluble sugar content, which was significantly higher than $\mathrm{RH}_{70 \%}$ and $\mathrm{RH}_{90 \%}$. At the same $\mathrm{RH}\left(\mathrm{RH}_{50 \%}\right.$ and $\left.\mathrm{RH}_{70 \%}\right)$, the soluble sugar content under the high temperature treatment of $41{ }^{\circ} \mathrm{C}$ was higher than that of $38^{\circ} \mathrm{C}$. It is worth noting that at $38^{\circ} \mathrm{C}$, the soluble sugar content under $\mathrm{RH}_{70 \%}$ treatment was not significantly different from $\mathrm{RH}_{90 \%}$ except for 12 -d treatment of leaves. At $41^{\circ} \mathrm{C}$, the soluble sugar content under $\mathrm{RH}_{70 \%}$ treatment was higher than $\mathrm{RH}_{90 \%}$, and with the extension of treatment time, this gap became increasingly significant, especially in leaves and roots.

Free amino acid concentrations. Under the conditions of high temperature and different RH conditions, the content of free amino acids in the leaves, stems, and roots of tomatoes was consistent (Fig. 4). The content of free amino acids under high temperature was significantly higher than that of $\mathrm{CK}$, and with the prolongation of the

Table 2. Effects of different treatments on the growth of tomato plants.

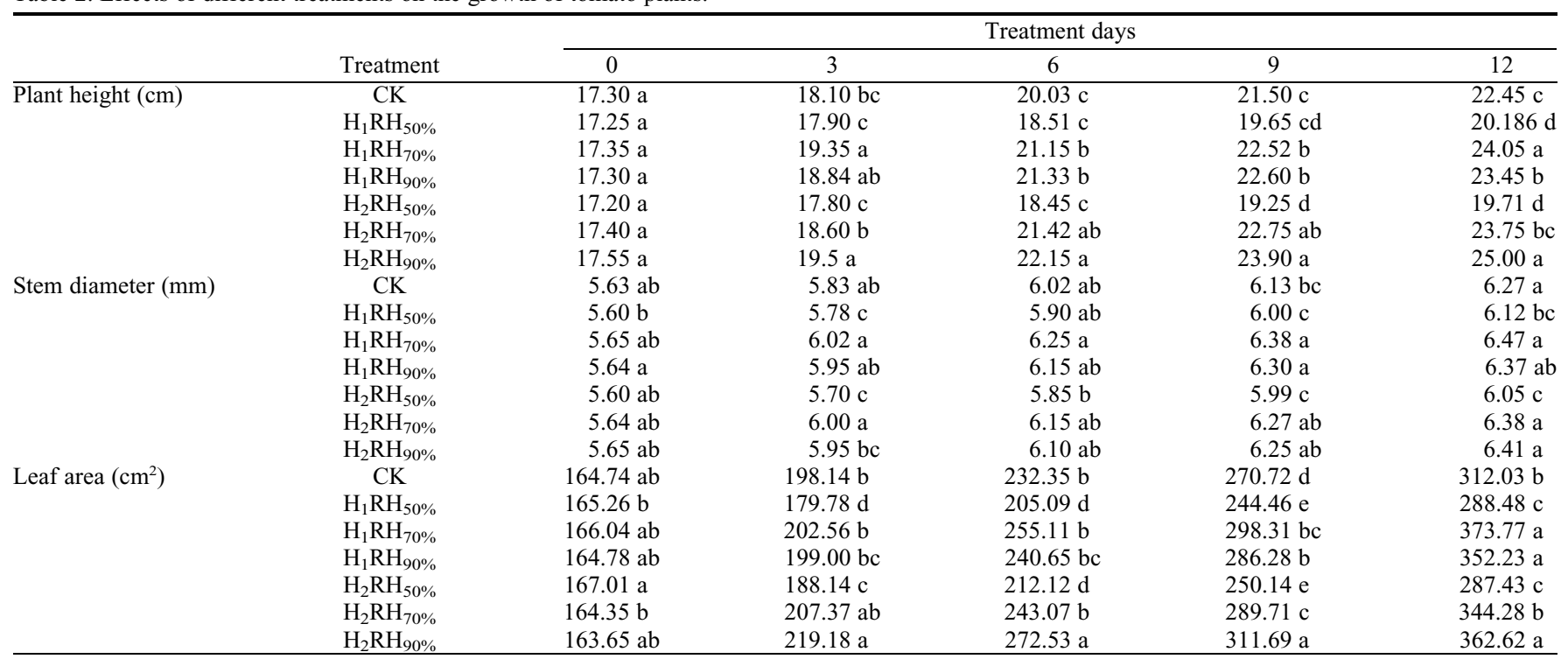

Different letters $(P<0.05)$ indicate significant differences within each column according to the Duncan's multiple range test. 


\section{Dry matter accumulation (g)}
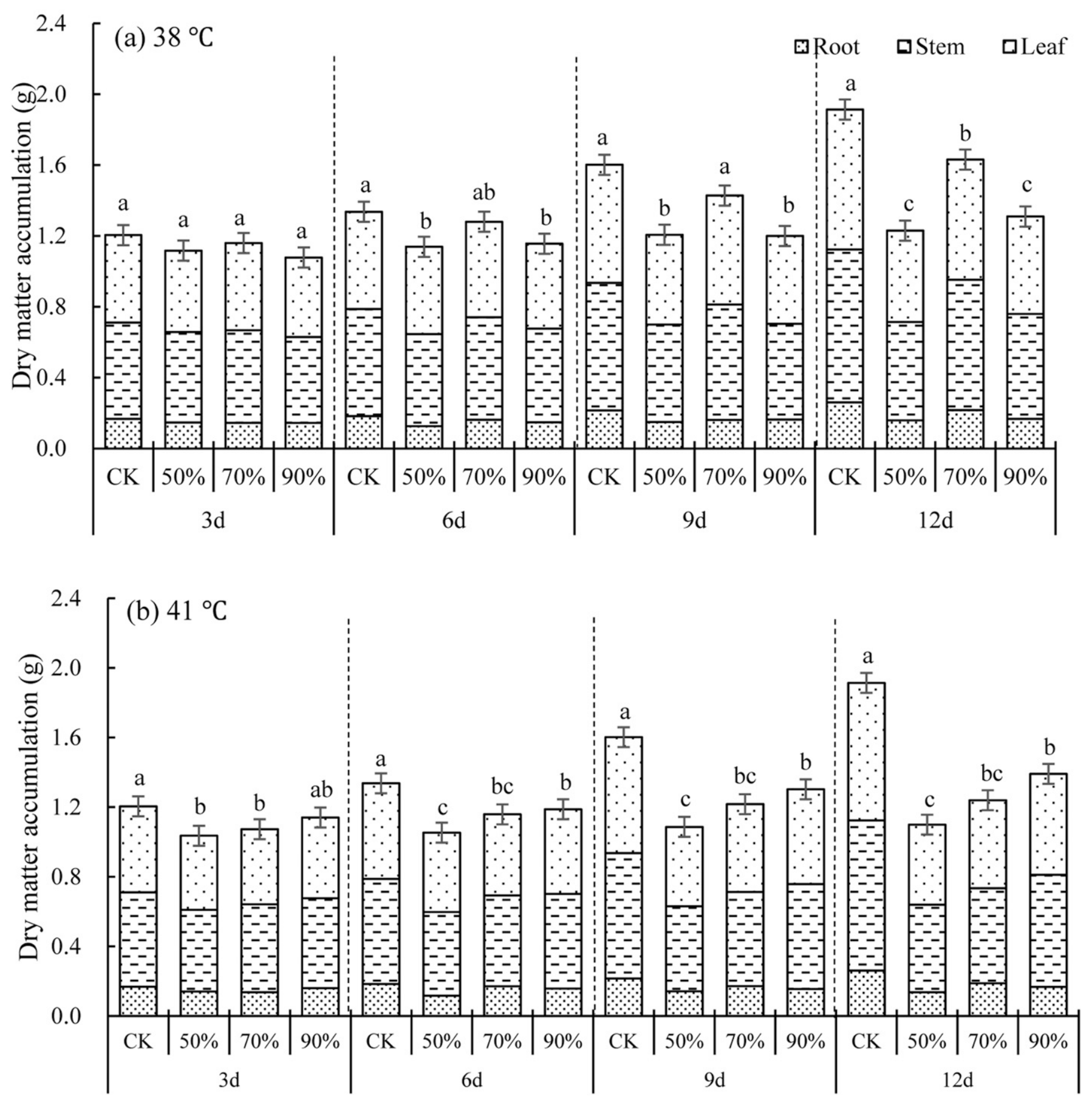

Fig. 2. Effects of different treatments on dry matter accumulation of tomato seedlings. Values with different letters show significant differences at $P<0.05$ between treatments. Values are means $\pm \mathrm{SD}, \mathrm{n}=3$.

treatment time, the content showed a clear increase trend under each humidity condition, especially $\mathrm{RH}_{90 \%}$ and $\mathrm{RH}_{70 \%}$. Under the same humidity, the content of free amino acids treated at $41{ }^{\circ} \mathrm{C}$ was slightly higher than that at $38^{\circ} \mathrm{C}$. At the same high temperature, the content of free amino acids under $\mathrm{RH}_{90 \%}$ treatment was the highest, followed by $\mathrm{RH}_{70 \%}$ treatment, and $\mathrm{RH}_{50 \%}$ treatment was the smallest.
$A B A$ concentrations. Under $\mathrm{CK}$ treatment, the content of ABA in tomato seedlings was the lowest, and the content under high temperature environment was significantly higher than $\mathrm{CK}$ after $3 \mathrm{~d}$ of treatment (Fig. 5A). With the increase of the treatment time, the ABA content increased significantly, and by $12 \mathrm{~d}$ of treatment, $\mathrm{H}_{1} \mathrm{M}$ and $\mathrm{H}_{2} \mathrm{H}$ were $91.49 \%$ and $94.68 \%$ higher than $\mathrm{CK}$, respectively. At $38^{\circ} \mathrm{C}$, the ABA content of $\mathrm{RH}_{70 \%}$ was the highest, which was close to the $\mathrm{RH}_{90 \%}$, whereas at $41{ }^{\circ} \mathrm{C}$, the $\mathrm{ABA}$ content of $\mathrm{RH}_{90 \%}$ was the highest, which was significantly higher than that of $\mathrm{RH}_{70 \%}$ and $\mathrm{RH}_{50 \%}$

IAA concentrations. Under CK treatment (normal temperature and humidity conditions), the IAA content in the top shoots of tomato seedlings was the highest, and the content under high temperature environment 


\section{Soluble sugar content $\left(\mathrm{mg} \cdot \mathrm{g}^{-1}\right)$}
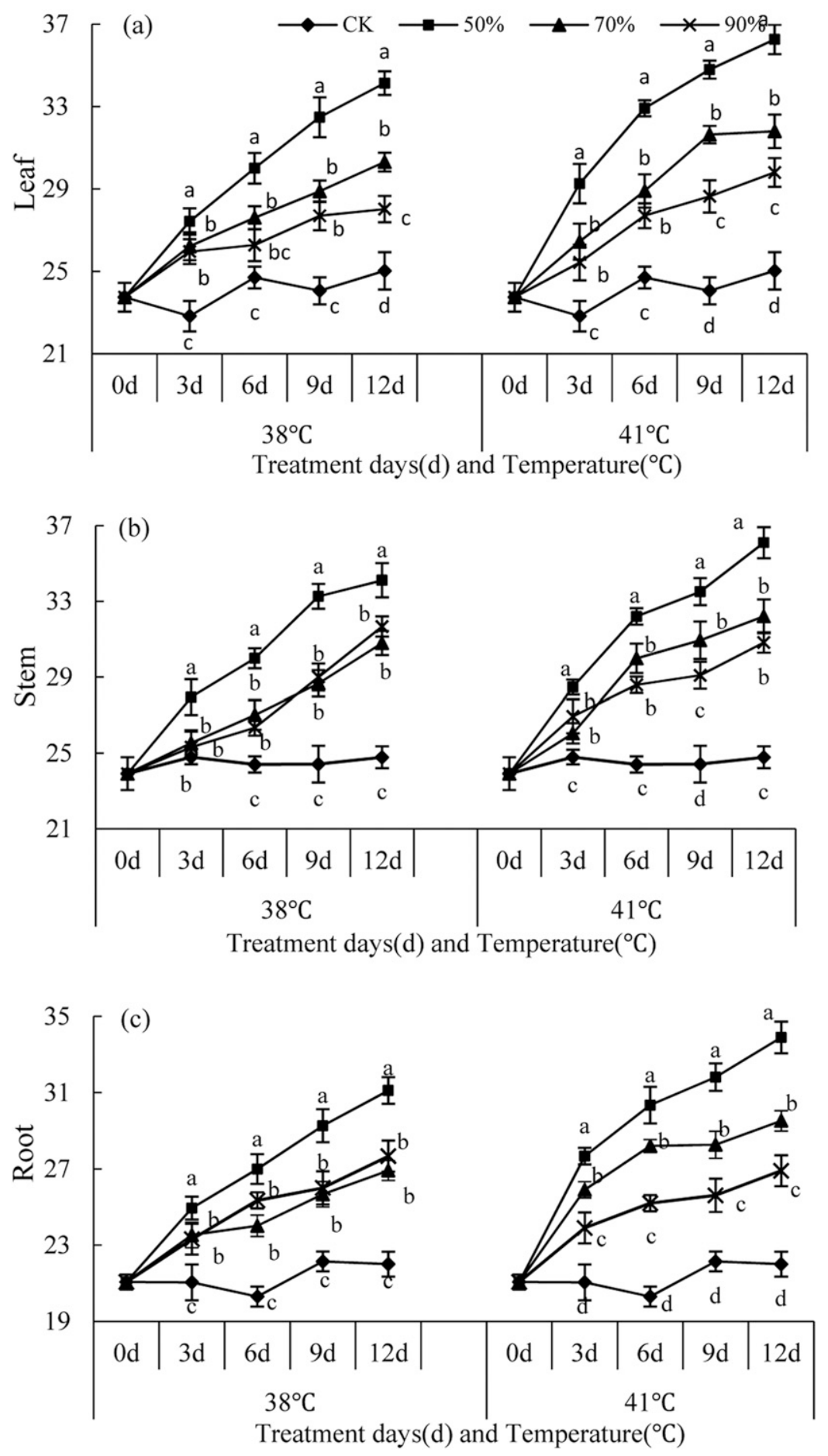

Fig. 3. Effects of different treatments on soluble sugar content in various organs of tomato. Values with different letters show significant differences at $P<0.05$ between treatments. Values are means $\pm \mathrm{SD}, \mathrm{n}=3$.

was significantly lower than that of $\mathrm{CK}$ (Fig. 5B). With the increase of the treatment time, the IAA content decreased significantly, and by $12 \mathrm{~d}$ of treatment, $\mathrm{H}_{1} \mathrm{~L}$ and $\mathrm{H}_{2} \mathrm{~L}$ were $48.28 \%$ and $51.47 \%$ lower than $\mathrm{CK}$, respectively. At $38{ }^{\circ} \mathrm{C}$, IAA content was the highest under $\mathrm{RH}_{90 \%}$, and $\mathrm{RH}_{50 \%}$ was the lowest, whereas at $41{ }^{\circ} \mathrm{C}$, IAA content of
$\mathrm{RH}_{70 \%}$ was the highest, which was 1.23 $\mu \mathrm{g} \cdot \mathrm{g}^{-1}$ higher than $\mathrm{RH}_{90 \%}$.

$\mathrm{GA}_{3}$ concentrations. Under CK treatment (normal temperature and humidity conditions), the content of $\mathrm{GA}_{3}$ in tomato seedlings was the lowest, and the content under high temperature environment was significantly higher than $\mathrm{CK}$ after $3 \mathrm{~d}$ of treatment
(Fig. 5C). With the increase of the treatment time, the $\mathrm{GA}_{3}$ content increased significantly, and by $12 \mathrm{~d}$ of treatment, $\mathrm{H}_{1} \mathrm{~L}$ and $\mathrm{H}_{2} \mathrm{~L}$ were $39.59 \%$ and $44.64 \%$ higher than $\mathrm{CK}$, respectively. Under the high temperature treatment, $\mathrm{GA}_{3}$ content at $\mathrm{RH}_{50 \%}$ humidity treatment was the highest, and there was no significant difference between $\mathrm{RH}_{70 \%}$ and $\mathrm{RH}_{90 \%}$.

ZT concentrations. The ZT content in the top buds of tomato seedlings under normal temperature and humidity (CK) was the highest (Fig. 5D). Under high temperature treatment, the ZT content was significantly lower than that of CK. With the increase of the treatment time, the content decreased significantly. By $12 \mathrm{~d}$ of treatment, $\mathrm{H}_{1} \mathrm{~L}$ and $\mathrm{H}_{2} \mathrm{~L}$ were $47.03 \%$ and $60.37 \%$ lower than $\mathrm{CK}$, respectively. Under the same high temperature environment, the ZT level was the highest under $\mathrm{RH}_{90 \%}$ humidity treatment, followed by $\mathrm{RH}_{70 \%}$, and under the same humidity environment, the ZT level under the treatment of $38^{\circ} \mathrm{C}$ was higher than that of $41{ }^{\circ} \mathrm{C}$.

Analysis of variance. After $12 \mathrm{~d}$ of treatment, the index values of tomato seedlings were analyzed by variance (Table 3 ). The results showed that the effects of varied high temperatures on plant height and stem diameter of tomato were not significant, whereas there were significant effects on leaf area and stem soluble sugars $(P<0.05)$. In addition, high temperatures had significant effects on the dry matter accumulation, endogenous hormones in the top buds, and free amino acid and soluble sugar concentrations in leaves and roots $(P<0.01)$. The effects of varied humidity levels on tomato plant growth and hormone concentrations were significant $(P<0.01)$. The influence of temperature and humidity on stem diameter, soluble sugar, and free amino acid concentrations in leaves were not significant, whereas the influence on the dry matter accumulation, free amino acids, and ABA was significant $(P<0.01)$.

\section{Discussion}

Previous studies have reported that high temperatures are detrimental to the growth and development of greenhouse tomatoes (Giri et al., 2017; Sang et al., 2016; Van Ploeg and Heuvelink, 2005). In this study, at 38 and $41^{\circ} \mathrm{C}$, the dry matter accumulation of tomato seedlings was significantly lower than that of CK (Fig. 2), indicating that the high temperature environment exerted stress on the growth of tomato plants, and the dry matter accumulation decreased, which is consistent with the results of Yang et al. (2020). In the short term (9 d), under the $38{ }^{\circ} \mathrm{C}$ high temperature and $\mathrm{RH}_{70 \%}$, the plant dry matter accumulation was not significantly different from $\mathrm{CK}$, indicating that the temperature and humidity environment has no obvious stress on plant growth; the high temperature of $41{ }^{\circ} \mathrm{C}$ obviously caused heat stress to the plants. $\mathrm{RH}_{70 \%}$ and $\mathrm{RH}_{90 \%}$ were significantly higher than $\mathrm{RH}_{50 \%}$, indicating that under $41{ }^{\circ} \mathrm{C}$ high temperature increasing 
Free amino acid content $\left(\mathrm{mg} \cdot 100 \mathrm{~g}^{-1}\right)$
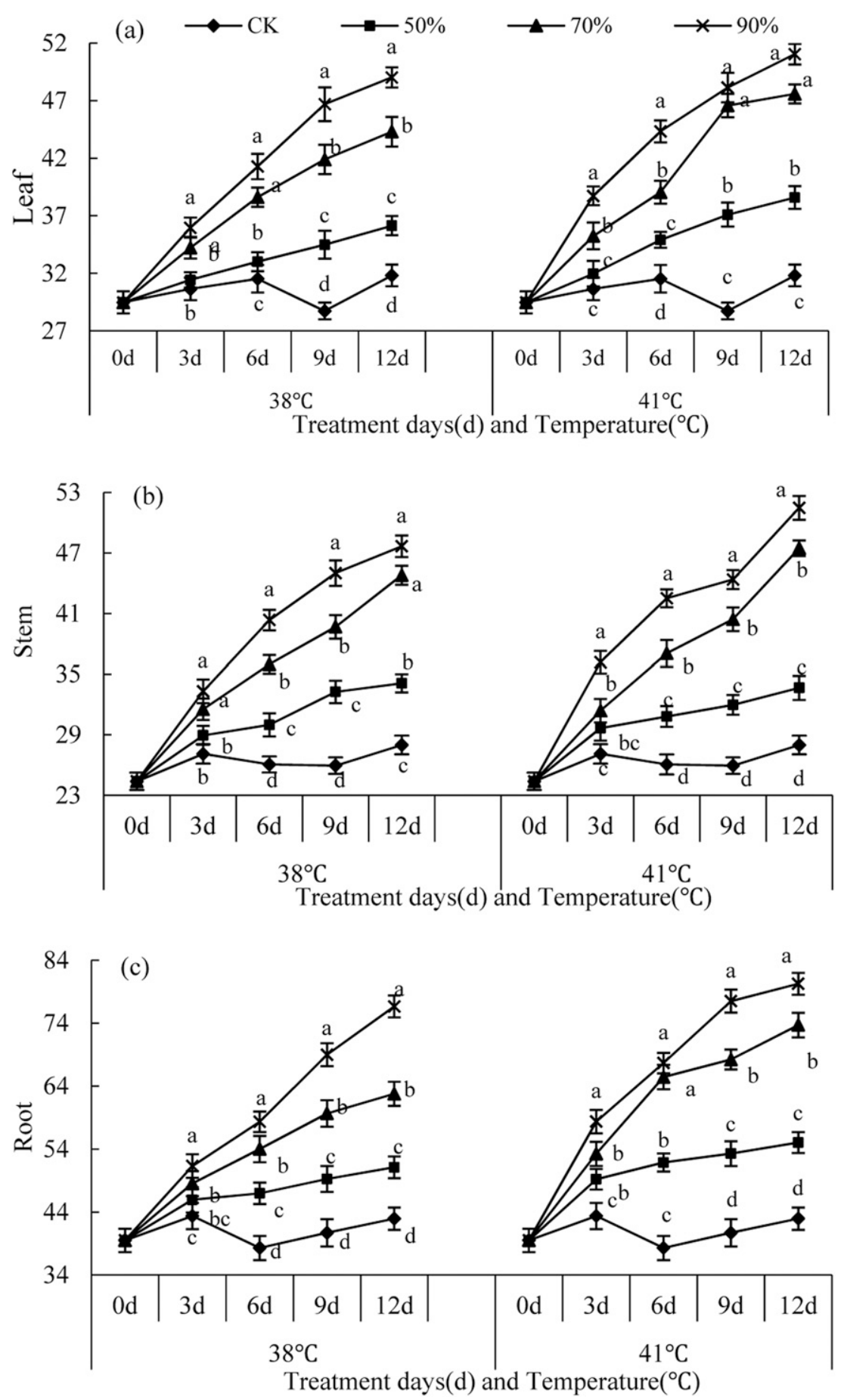

Fig. 4. Effect of different treatments on free amino acid content in various organs of tomato. Values with different letters show significant differences at $P<0.05$ between treatments. Values are means $\pm \mathrm{SD}, \mathrm{n}=3$.

the $\mathrm{RH}$ to above $70 \%$ can alleviate high temperature stress. In summary, increasing the RH to $70 \%$ in a high-temperature environment can effectively alleviate hightemperature stress. In our study (Table 2), the tomato plant height, stem diameter, and leaf area measured after high temperature were higher than CK, mainly due to the stress compensation effect of the plant.

Soluble sugar can be used as an osmotic adjustment substance when the plant is under adverse conditions, it can adjust the concentration of cell fluid and enhance the stress resistance of crops (Barickman et al., 2016;
Zhang et al., 2005). Du et al. (2010) showed that the soluble sugar content of thread pepper leaves increases significantly at high temperatures. Cao et al. (2011) found that increasing air humidity at high temperatures can significantly reduce the soluble sugar content in the roots and leaves of seedlings. The results of this study showed that the changes of soluble sugar content in various organs of tomato seedlings treated with three kinds of air humidity at high temperature were basically the same, all of which showed that the soluble sugar content of leaves, stems and roots of tomato seedlings was higher than CK under each treatment, this is consistent with the results obtained by previous studies (Huang et al., 2010) that increased the content of soluble sugar in plants without humidification at high temperature. Under high temperature, when the RH was increased, its content decreased significantly $(P<0.05)$, and the higher the treatment temperature, the higher the soluble sugar content. Wang et al. (2006) found that at 28 to $44{ }^{\circ} \mathrm{C}$, with the increase of high temperature stress, the soluble sugar content of tomato increased, but if the variety has strong heat resistance, the increase was small, indicating that the degree of damage is negligable. Under the high temperature environment, with the extension of the treatment time, the soluble sugar content in tomato organs under $\mathrm{RH}_{70 \%}$ and $\mathrm{RH}_{90 \%}$ increased slowly, whereas the soluble sugar content under $\mathrm{RH}_{50 \%}$ treatment increased sharply (Fig. 3), indicating that $50 \%$ of the RH environment during the high temperature treatment exerts severe stress on tomato plants, and the higher RH can effectively alleviate the high temperature stress. It can be seen that increasing the air humidity can reduce the soluble sugar content of tomatoes so that they are more used for growth rather than as a stress osmotic adjustment substance.

Free amino acids are also a key osmotic substance in plants; their concentration is low under normal conditions, but the concentration in adverse conditions will increase rapidly, and the amplitude is positively related to heat resistance (Karami Mehrian et al., 2015; Parida and Das, 2005). Our research showed that under high temperature conditions, the content of free amino acids in leaves, stems, and roots of tomato seedlings increased significantly, and the this increased further with temperature. The content was highest under $\mathrm{RH}_{90 \%}$ and lowest under $\mathrm{RH}_{50 \%}$, indicating that under high temperature treatment, free amino acids in tomato seedlings act as osmotic adjustment substances and participate in resisting adversity. The higher the temperature, the greater the content of free amino acids in the plant, which means the more severe the stress on the plant. Under $\mathrm{RH}_{90 \%}$, the content of free amino acids was significantly higher than that of $\mathrm{RH}_{50 \%}$ and $\mathrm{RH}_{70 \%}$, indicating that under this humidity treatment, a large number of amino acids were produced in tomato seedlings to resist stress, which means the stress resistance of plants under this humidity was significantly improved. 
The content of free amino acids in the roots of tomato seedlings was obviously higher than that in leaves and stems, mainly because the roots are the main nitrogen absorbing organs, which are in direct contact with the soil and are important nitrogen reservoirs for plants, so the content of free amino acids is higher than that of the ground growth parts. The free amino acids content in the root system increased more than that of leaves and stems ing that under high temperature stress, the root system absorbed or produced more free amino acids to resist adversity.

As a stress hormone, ABA is an important signal substance for plants to respond to stress (Leung and Giraudat, 1998; Nambara and Marion-Poll, 2005), and it will regulate plants to respond to many multiple environmental stresses. ABA is a signal substance that responds to heat stress (Larkindale, 2002). By activating the synthesis of ABA, inhibiting its degradation, or unlinking the conjugated form, it increases the ABA content in stressed plants (Boursiac et al., 2013; Song et al., 2014). Adversity stress can induce a large amount of ABA accumulation in plants by adjusting the metabolic balance, with the extension of treatment time, indicat-

improving the plant's adaptability to stress and resistance to stress. Mao et al. (2005) found that under high temperature stress, the ABA content of heat-tolerant tomato varieties increased more than that of heat-sensitive varieties, and the ABA content in floral organs of heat-tolerant varieties is higher than that of heat-sensitive varieties regardless of whether they are at normal or high temperature. In this study, the ABA concentration in the top buds of tomato plants also showed an increasing trend at high temperatures, and the ABA concentration increased significantly when the humidity increased, indicating that increasing humidity can enhance the heat resistance of the plants. Under high temperature conditions, the ABA content was the lowest under $\mathrm{RH}_{50 \%}$. It may be that the self-regulating ability of the plants under this temperature and humidity condition has been damaged, and it has already caused extremely severe stress. The increase in the ABA content of tomato plants not only protects against light inhibition and induces or increases the expression of resistance genes to enhance the plant's ability to adapt to high temperatures (Alamillo and Bartels, $2001)$, it can also increase the activity of

endogenous hormone content $\left(\mu \mathrm{g} \cdot \mathrm{g}^{-1}\right)$
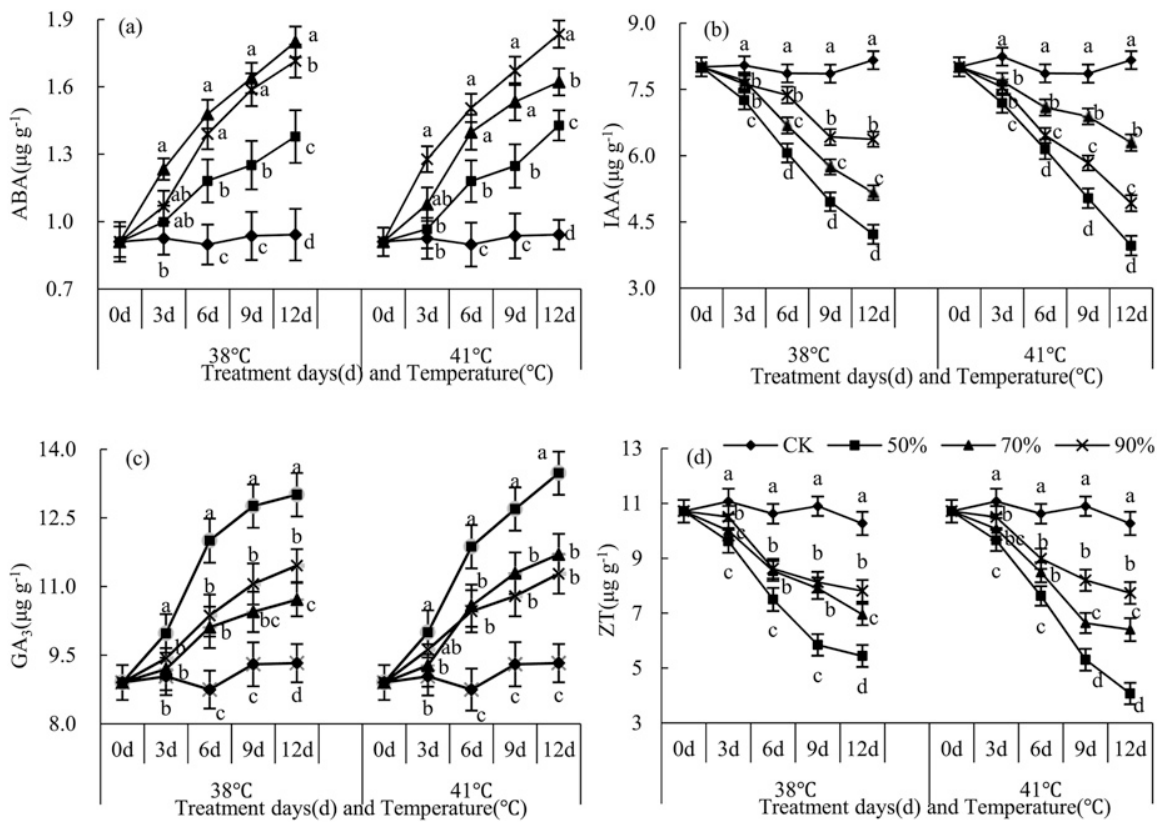

Fig. 5. Effect of different treatments on endogenous hormone content in top bud of tomato. Values with different letters show significant differences at $P<0.05$ between treatments. Values are means $\pm \mathrm{SD}, \mathrm{n}=3$. antioxidant enzymes such as SOD, POD, and $\mathrm{CAT}$, and reduce the damage to the cell membrane system caused by oxygen free radicals produced by stress ( $\mathrm{Li}$ et al., 2006).

IAA is involved in regulating almost all growth and development processes of plants and has the functions of regulating the growth rate of stems, inhibiting lateral buds, and promoting rooting (Celis-Arámburo et al., 2011; Sunita et al., 2011). At present, there are few studies on the effects of IAA under high temperature stress; however, the current research results indicate that high temperature stress changes the response of IAA by changing its biosynthesis ( $\mathrm{Li}$ et al., 2012). When the plant is subjected to high temperature stress, growth and development are ended or cell death, which causes the content of IAA to decrease. Duan (2010) found that under high temperature stress, the content of IAA in heat-tolerant varieties was higher than that of heat-sensitive varieties. It can be said that the IAA content is positively correlated with its heat resistance (Shen et al., 2006). In this study, the concentration of IAA in the top bud decreased at high temperature, consistent with the conclusions mentioned earlier. Under high temperature environment, IAA content under $\mathrm{RH}_{50 \%}$ was significantly less than that of $\mathrm{RH}_{70 \%}$ and $\mathrm{RH}_{90 \%}$. This indicates that when the $\mathrm{RH}$ is $50 \%$ under high temperature conditions, the self-regulation ability of tomato plants is destroyed, which causes extremely severe stress on tomatoes. Increasing the RH to above $70 \%$ can effectively alleviate high-temperature stress.

$\mathrm{GA}_{3}$ can promote plant flower bud differentiation, induce flowering, and promote fruit ripening (Sharmshiri and Singh, 2009). It is mostly found in vigorous plant organs and is an important hormone for regulating plant height (Wolbang et al., 2004). GA 3 can affect the stress resistance of plants by regulating the content of free water and bound water in plants. Studies have found that plants with low $\mathrm{GA}_{3}$ content have better tolerance (Sarkar et al., 2004). In this study, the $\mathrm{GA}_{3}$ content of tomato plants increased under high temperature, and the content under $\mathrm{RH}_{70 \%}$ and $\mathrm{RH}_{90 \%}$ was significantly less than that of $\mathrm{RH}_{50 \%}$, indicating that under high temperature conditions, $\mathrm{RH}$ above $70 \%$ has better heat resistance. However, some studies have found that $\mathrm{GA}_{3}$ content shows a downward trend at high temperatures (Teng et al., 2010; Wang and Xiong, 2016). This demonstrates that the dynamic change of plant $\mathrm{GA}_{3}$ under high temperature stress is closely related to the nature of the plant itself. Therefore, the role of $\mathrm{GA}_{3}$ in tomato plants under high temperature stress remains to be further explored.

Table 3. Analysis of variance table.

\begin{tabular}{|c|c|c|c|c|c|c|c|c|c|c|c|c|c|c|}
\hline & $\begin{array}{c}\text { Plant } \\
\text { ht }\end{array}$ & $\begin{array}{l}\text { Stem } \\
\text { diam }\end{array}$ & $\begin{array}{l}\text { Leaf } \\
\text { area }\end{array}$ & $\mathrm{ZT}$ & GA3 & IAA & $\mathrm{ABA}$ & $\begin{array}{l}\text { Leaf SS } \\
\text { content }\end{array}$ & $\begin{array}{c}\text { Stem SS } \\
\text { content }\end{array}$ & $\begin{array}{c}\text { Root SS } \\
\text { content }\end{array}$ & $\begin{array}{c}\text { Leaf free } \\
\text { AA content }\end{array}$ & $\begin{array}{c}\text { Stem free } \\
\text { AA content }\end{array}$ & $\begin{array}{c}\text { Root free } \\
\text { AA content }\end{array}$ & $\begin{array}{c}\text { Dry matter } \\
\text { accumulation }\end{array}$ \\
\hline Temperature & NS & NS & $*$ & $* *$ & $* *$ & $* *$ & $* *$ & $* *$ & * & $* *$ & $* *$ & $* *$ & $* *$ & $* *$ \\
\hline Humidity & $* *$ & $* *$ & $* *$ & $* *$ & $* *$ & $* *$ & $* *$ & $* *$ & $* *$ & $* *$ & $* *$ & $* *$ & $* *$ & $* *$ \\
\hline $\mathrm{T} \times \mathrm{H}$ & $* *$ & NS & $* *$ & $* *$ & $* *$ & $* *$ & $*$ & NS & $* *$ & $* *$ & NS & $*$ & $* *$ & $* *$ \\
\hline
\end{tabular}

$\mathrm{AA}=$ amino acid; $\mathrm{ABA}=$ abscisic acid; $\mathrm{GA}_{3}=$ gibberellin; $\mathrm{IAA}=$ indole acetic acid; $\mathrm{SS}=$ soluble sugar; $\mathrm{ZT}=$ cytokinin .

NS, *, **Nonsignificant or significant at $P<0.05$ or 0.01 , respectively. 
ZT is an important phytohormone, mainly produced in roots, involved in various physiological processes such as plant cell division, chlorophyll synthesis, leaf and shoot formation, and leaf senescence (Binns, 1994). ZT is involved in the development of chloroplast and thylakoid lamina, thereby delaying the senescence of leaves under stress (Hare et al., 1997). It can also increase the activity of membrane protective enzymes, such as SOD; directly or indirectly scavenge free radicals; and reduce the ratio of lipid peroxidation and membrane fatty acid composition to protect the integrity of cell membrane structure and function (Wang, 2000). In this study, under high temperature, the ZT content of tomato seedling top buds showed a downward trend, and the ZT content under $\mathrm{RH}_{50 \%}$ was significantly lower than $\mathrm{RH}_{70 \%}$ and $\mathrm{RH}_{90 \%}$, indicating that $50 \%$ $\mathrm{RH}$ at high temperature can accelerate the senescence of tomatoes. Increasing the $\mathrm{RH}$ can increase the ZT content of tomato plants, help to reduce the content of free water, delay the yellowing of leaves and maintain the stability of cell membranes, thereby improving the high temperature resistance of tomatoes.

\section{Conclusion}

This study investigated the effects of the interactions between daily maximum temperatures of 38 and $41{ }^{\circ} \mathrm{C}$ and various relative humidity levels on the growth and endogenous hormone concentrations in tomato seedlings. It was observed that increasing humidity to $\approx 70 \%$ in a high temperature environment was beneficial to the growth of tomato. Generally, in humid environments with $\geq 70 \%$ of relative humidity, plant growth at $38{ }^{\circ} \mathrm{C} / 18{ }^{\circ} \mathrm{C}$ was slightly better than that at $41{ }^{\circ} \mathrm{C} / 18{ }^{\circ} \mathrm{C}$. This suggests that increasing humidity could enhance heat resistance in tomato plants within a certain temperature range. The results contributes to a better understanding of the interactions between microclimate parameters inside a Venlo-type glass greenhouse environment, in a specific climate condition, and their effects on the growth of tomato. Now, because Venlo-type greenhouses are becoming popular for urban farming as rooftop greenhouses (Shamshiri et al., 2018b), this study is a step toward engineering such greenhouses under the specific climate conditions. These results can be directly incorporated in updating databases of decision support systems and adaptive analysis frameworks (Shamshiri et al., 2017c) that are interfaced with yield prediction models for dynamic assessment of microclimate and control (Shamshiri et al., 2017d, 2020). In addition, this study indirectly contributes to reducing risks of greenhouse tomato production and increasing profit.

\section{Literature Cited}

Alamillo, J.M. and D. Bartels. 2001. Effects of desiccation on photosynthesis pigments and the ELIP-like dsp 22 protein complexes in the resurrection plant Craterostigma plantagineum. Plant Sci. 160:1161-1170.

Barickman, T.C., D.A. Kopsell, and C.E. Sams. 2016. Abscisic acid improves tomato fruit quality by increasing soluble sugar concentrations. J. Plant Nutr. 40:964-973.

Binns, A.N. 1994. Cytokinin accumulation and action: Biochemical, genetic, and molecular approaches. Annu. Rev. Plant Physiol. Plant Mol. Biol. 45:173-196.

Boursiac, Y., S. Léran, C. Corratgé-Faillie, G. Alain, and K. Gabriel. 2013. ABA transport and transporters. Trends Plant Sci. 18:325-333.

Cao, J., X. Wen, and Y. Li. 2011. Effect of relative humidity on glucose metabolism of tomato plants in greenhouse (in Chinese). J. Shanxi Agric. Univ., Nat. Sci. Ed. 31:235-238.

Celis-Arámburo, T.J., M. Carrillo-Pech, L.A. CastroConcha, L. Miranda-Ham M, M. MartínezEstévez, and I. Echevarría-Machado. 2011. Exogenous nitrate induces root branching and inhibits primary root growth in Capsicum chinense Jacq. Plant Physiol. Biochem. 49:12-18.

Chevuturi, A., N.P. Klingaman, A.G. Turner, and S. Hannah. 2018. Projected Changes in the Asian-Australian Monsoon Region in $1.5^{\circ} \mathrm{C}$ and $2.0^{\circ} \mathrm{C}$ Global-Warming Scenarios. Earths Futur. 6:339-358.

Cruz-Ortega, R., G. Ayala-Cordero, and A.L. Anaya. 2002. Allelochemical stress produced by the aqueous leachate of Callicarpa acuminata: Effects on roots of bean, maize, and tomato. Physiol. Plant. 116:20-27.

David, W.L. 2002. Carbon and nitrogen assimilation in relation to yield: Mechanisms are the key to understanding production systems. J. Expt. Bot. 53:773-787.

Du, L., Z. Zhao, Z. Gong, J. Guo, Z. Niu, and Y. Guo. 2010. Effects of water stress on the osmotic regulation of pepper leaves (in Chinese). Agr. Res Arid Regions 28:188-198.

Duan, H. 2010. Effect of high-temperature during heading and grain filling on grain quality and endogenous hormones of rice. MS Thesis, Yangzhou University.

Giri, A., S. Heckathorn, S. Mishra, and C.J.P. Krause. 2017. Heat stress decreases levels of nutrient-uptake and -assimilation proteins in tomato roots. Plants 6:6.

Hare, P.D., W.A. Cress, and J. Van Staden. 1997. Cytokinins and Water Stress: The involvement of cytokinins in plant responses to environmental stress. Plant Growth Regulat. 23:79-103.

Harel, D., H. Fadida, A. Slepoy, S. Gantz, and K. Shilo. 2014. The effect of mean daily temperature and relative humidity on pollen, fruit set and yield of tomato grown in commercial protected cultivation. Agronomy 4:167-177.

Hou, S., J. Zhu, M. Ding, and G. Lv. 2008. Simultaneous determination of gibberellic acid, indole-3-acetic acid and abscisic acid in wheat extracts by solid-phase extraction and liquid chromatography-electrospray tandem mass spectrometry. Talanta 76:798-802.

Huang, Y., Y. Li, and X. Wen. 2010. Effects of different air humidity on tomato's vegetative growth in greenhouse at high temperature (in Chinese). Northern Gardening 15:138-143.

Intergovernmental Panel on Climate Change. 2018. Global Warming of $1.5^{\circ} \mathrm{C}$. An IPCC Special Report on the impacts of global warming of $1.5^{\circ} \mathrm{C}$ above pre-industrial levels and related global greenhouse gas emission pathways, in the context of strengthening the global response to the threat of climate change, sustainable development, and efforts to eradicate poverty. 20 July 2020 . <https://www.ipcc.ch/site/assets/
uploads/sites/2/2019/06/SR15_Full_Report_ High_Res.pdf>.

Jin, C.Y. 2011. Study on growth and physiological metabolism of tomato seedlings under high temperature stress. MS Thesis, Nanjing Agricultural University.

Karami Mehrian, S., R. Heidari, and F. Rahmani. 2015. Effect of silver nanoparticles on free amino acids content and antioxidant defense system of tomato plants. Indian J. Plant. Physiol. 20:257-263.

Larkindale, J. 2002. Protection against heat stressinduced oxidative damage in arabidopsis involves calcium, abscisic acid, ethylene, and salicylic acid. Plant Physiol. 128:682-695.

Leung, J. and J. Giraudat. 1998. Abscisic acid signal transduction. Annu. Rev. Plant Biol. 49:199-222.

Li, J. 2014. Response of stomatal conductance and phytohormones of leaves to vapor pressure deficit in some species of plants. PhD Diss, Shan Dong University, Shandong Province.

Li, J., J. Cui, and X. Mi. 2012. Progress of studies on relationship between auxin and plant response to abiotic stress. Biotechnol. Bull. 36:13-17.

Li, X., Q. Chen, L. Wang, and L. Hao. 2006. Effects of abscisic acid on photosynthesis and antioxidant enzymes in wheat seedling (in Chinese). J. Shenyang Norm. Univ., Nat. Sci. Ed. 24:221-223.

Mao, S., Y. Du, X. Wang, D. Zhu, J. Gao, and S. Dai. 2005. Changes of endogenous abscisic acid and the effent of exogenous aba on pollen germination under heat stress tomato. Acta Hort. Sin. 32:234-238.

Mulholland, B.J., R.N. Edmondson, M. Fussell, J. Basham, and L.C. Ho. 2003. Effects of high temperature on tomato summer fruit quality. J. Hort. Sci. Biotechnol. 78:365-374.

Nambara, E. and A. Marion-Poll. 2005. Abscisic acid biosynthesis and catabolism. Annu. Rev. Plant Biol. 56:165-185.

Parida, A.K. and A.B. Das. 2005. Salt tolerance and salinity effects on plants: A review. Ecotoxicol. Environ. Saf. 60:324-349.

Peet, M., S. Sato, C. Clément, and E. Pressman. 2003. Heat stress increases sensitivity of pollen, fruit and seed production in tomatoes (Lycopersicon esculentum Mill.) to nonoptimal vapor pressure deficits. Acta Hort. 618:209-215.

Rohn, S., H.M. Rawel, and J. Kroll. 2002. Inhibitory effects of plant phenols on the activity of selected enzymes. J. Agr. Food Chem. 50:3566-3571.

Sang, Q.Q., S. Shu, X. Shan, S.R. Guo, and J. Sun. 2016. Effects of exogenous spermidine on antioxidant system of tomato seedlings exposed to high temperature stress. Russ. J. Plant Physiol. 63:645-655.

Sarkar, S., M.R. Perras, D.E. Falk, R. Zhang, R.P. Pharis, and R. Austin Fletcher. 2004. Relationship between gibberellins, height, and stress tolerance in barley (Hordeum vulgare L.) seedlings. Plant Growth Regulat. 42:125-135.

Shamshiri, R.R. 2017a. Measuring optimality degrees of microclimate parameters in protected cultivation of tomato under tropical climate condition. Measurement 106:236-244.

Shamshiri, R.R., I. Bojic, E. van Henten, S.K. Balasundram, V. Dworak, M. Sultan, and C. Weltzien. 2020. Model-based evaluation of greenhouse microclimate using IoT-Sensor data fusion for energy efficient crop production. J. Clean. Prod. 263:121303.

Shamshiri, R.R., H. Che Man, A.J. Zakaria, P.V. Beveren, W.I. Wan Ismail, and D. Ahmad. 
2017b. Membership function model for defining optimality of vapor pressure deficit in closed-field cultivation of tomato. Acta Hort. 1152:281-290.

Shamshiri, R.R., J.W. Jones, K.R. Thorp, D. Ahmad, H. Che Man, and S. Taheri. 2018a. Review of optimum temperature, humidity, and vapour pressure deficit for microclimate evaluation and control in greenhouse cultivation of tomato: A review. Intl. Agrophys. 32:287-302.

Shamshiri, R.R., F. Kalantari, K.C. Ting, K.R. Thorp, I.A. Hameed, C. Weltzien, D. Ahmad, and Z.M. Shad. 2018b. Advances in greenhouse automation and controlled environment agriculture: A transition to plant factories and urban agriculture. Intl. J. Agr. Biol. Eng. 11:122.

Shamshiri, R.R., M.R. Mahadi, K.R. Thorp, W.I.W. Ismail, D. Ahmad, and H.C. Man. 2017c. Adaptive management framework for evaluating and adjusting microclimate parameters in tropical greenhouse crop production systems. Plant Eng. 9:167-191.

Shamshiri, R.R. and R. Singh. 2009. Gibberellic acid influences the production of malformed and button berries, and fruit yield and quality in strawberry (Fragaria $\times$ ananassa Duch.). Sci. Hort. 119:430-433.

Shamshiri, R.R., P. van Beveren, H. Che Man, and A.J. Zakaria. 2017d. Dynamic Assessment of air temperature for tomato (Lycopersicon esculentum Mill) cultivation in a naturally ventilated net-screen greenhouse under tropical lowlands climate. J. Agr. Sci. Technol. 19:59-72.

Shao, T., L. Li, Y. Wu, M. Chen, X. Long, H. Shao, Z. Liu, and Z. Rengel. 2016. Balance between salt stress and endogenous hormones influence dry matter accumulation in Jerusalem artichoke. Sci. Total Environ. 568:891-898.

Shen, H., Y. Liu, and J. Yu. 2006. Relationship between heat-tolerance and endogenesis hormone content in pak choi. Jiangsu Agricultural Sciences 000:207-210.

Singh, U., P.K. Patel, A.K. Singh, V. Tiwari, R. Kumar, N. Rai, A. Bahadur, S.K. Tiwari, M. Singh, and B. Singh. 2015. Screening of tomato genotypes under high temperature stress for reproductive traits. Vegetable Science 42:52-55.

Song, Y., Y. Miao, and C. Song. 2014. Behind the scenes: The roles of reactive oxygen species in guard cells. New Phytol. 201:1121-1140.

Sunita, Y., A. David, and S.C. Bhatla. 2011. Nitric oxide accumulation and actin distribution during auxin-induced adventitious root development in sunflower. Scientia Hort. 129:159-166.

Teng, Z., L. Zhi, J. Lv, X. Zong, S. Wang, and G. He. 2010. Effects of high temperature on photosynthesis characteristics, phytohormones and grain quality during filling-periods in rice (in Chinese). Acta Ecol. Sin. 30:6504-6511.

Van Ploeg, D. and E. Heuvelink. 2005. Influence of sub-optimal temperature on tomato growth and yield: A review. J. Hort. Sci. Biotechnol. 80:652-659.

Wang, S.G. 2000. Roles of cytokinin on stressresistance and delaying senescence in plants (in Chinese). Chinese Bul. of Bot. 17:121-126.

Wang, D., L. Kang, X. Xu, and J. Li. 2006. Effect of heat stress on main physiological and biochemical indexes of tomato leaves (in Chinese with English abstract). Paper presented at the Seventh Youth Academia Symposium of Chinese Horticulture Society Advances in Horticulture (7). China Agricultural Press, Beiijing. 2006:898-901.

Wang, R. and X. Xiong. 2016. Effect of temperature stress on growth and metabolism in perennial ryegrass (in Chinese). Acta Pratura Sinica 25:81-90.

Wang, L., Z. Yang, M. Wang, S. Yang, X. Cai, and J. Zhang. 2018. Effect of air humidity on nutrient content and dry matter distribution of tomato seedlings under high temperature (in Chinese). Chinese J. Agrometeorology 39:304 313.

Wang, L., Z. Yang, S. Yang, J. Li, K. Li, and M. Hou. 2017. Effects of high temperature and different air humidity on growth and senescence characteristics for tomato seedlings (in Chinese). Chinese J. Agrometeorology 38:761-770.

Wolbang, C.M., P.M. Chandler, J.J. Smith, and J.J. Ross. 2004. Auxin from the developing inflorescence is required for the biosynthesis of active gibberellins in barley stems. Plant Physiol. 134:769-776.

Xue, Y., Y. Li, and X. Wen. 2010. Effects of air humidity on the photosynthesis and fruit-set of tomato under high temperature (in Chinese) Acta Hort. Sin. 37:397-404.

Yang, H., X. Gu, M. Ding, W. Lu, and D. Lu. 2020. Weakened carbon and nitrogen metabolisms under post-silking heat stress reduce the yield and dry matter accumulation in waxy maize. $\mathrm{J}$. Integr. Agr. 19:78-88.

Yang, S., Z. Yang, X. Cai, L. Wang, and X. Zhou. 2018a. Simulation of light response of photosynthesis for greenhouse tomato leaves under high temperature and high humidity stress (in Chinese). Chinese J. Ecology 37:2003-2012.

Yang, S., Z. Yang, L. Wang, J. Li, M. Zhang, and K. Li. 2018b. Effect of high humidity and high temperature interaction on photosynthetic characteristics of greenhouse tomato crops (in Chinese). Chinese J. Ecology 37:57-63.

Zhang, J., T. Li, and J. Xu. 2005. Effects of daytime sub-high temperature on greenhouse tomato growth, development, yield and quality. Chin. J. Appl. Ecol. 16:1051-1055.

Zhang, G., S. Zhang, L. Xiao, X. Wu, Y. Xiao, and L. Chen. 2013. Physiological responses of anther to high temperature stress in rices. Plant Physiol. J. Hsun 49:923-928.

Zhao, H., Z. Yang, M. Wang, T. Wei, L. Wang, Q. Sun, and X. Zhang. 2019. Effects of high temperature and high humidity stress and restoration on the fast fluorescence induction dynamics of tomato leaves (in Chinese). Chinese J. Ecology 38:2405-2413.

Zheng, H., Q. Zhang, J. Quan, Q. Zheng, and W. Xi. 2016. Determination of sugars, organic acids, aroma components, and carotenoids in grapefruit pulps. Food Chem. 205(Aug.15): $112-121$.

Zou, X., Y. Hu, D. Wei, S. Chen, P. Wu, and X. Ma. 2019. Correlation between endogenous hormone and the adaptability of Chinese fir with high phosphorus-use efficiency to low phosphorus stress. Acta Phytoecol. Sin. 43:139151. 